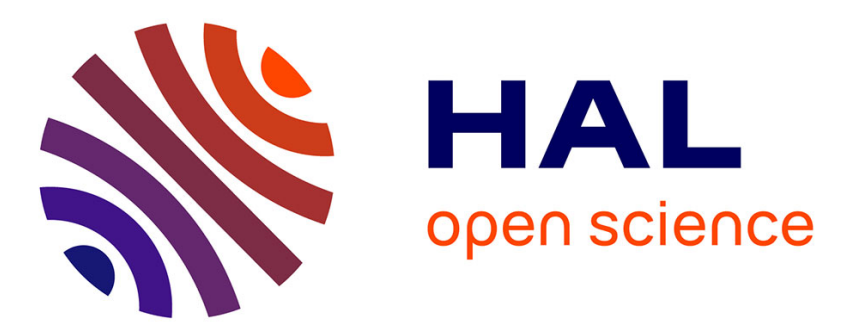

\title{
Determinants of the prevalence of the cloacal cestode in teal wintering in the French Camargue
}

\author{
Andy J. Green, Boyko B. Georgiev, Anne-Laure Brochet, Michel \\ Gauthier-Clerc, Hervé Fritz, Matthieu Guillemain
}

\section{- To cite this version:}

Andy J. Green, Boyko B. Georgiev, Anne-Laure Brochet, Michel Gauthier-Clerc, Hervé Fritz, et al. Determinants of the prevalence of the cloacal cestode in teal wintering in the French Camargue. European Journal of Wildlife Research, 2010, 57 (2), pp.275-281. 10.1007/s10344-010-0424-7 . hal00615127

\section{HAL Id: hal-00615127 \\ https://hal.science/hal-00615127}

Submitted on 18 Aug 2011

HAL is a multi-disciplinary open access archive for the deposit and dissemination of scientific research documents, whether they are published or not. The documents may come from teaching and research institutions in France or abroad, or from public or private research centers.
L'archive ouverte pluridisciplinaire HAL, est destinée au dépôt et à la diffusion de documents scientifiques de niveau recherche, publiés ou non, émanant des établissements d'enseignement et de recherche français ou étrangers, des laboratoires publics ou privés. 


\title{
Determinants of the prevalence of the cloacal cestode Cloacotaenia megalops in teal wintering in the French Camargue
}

\author{
Andy J. Green • Boyko B. Georgiev • \\ Anne-Laure Brochet • Michel Gauthier-Clerc • \\ Hervé Fritz • Matthieu Guillemain
}

Received: 4 December 2009 /Revised: 16 June 2010 / Accepted: 3 August 2010 /Published online: 18 August 2010

(C) Springer-Verlag 2010

\begin{abstract}
Eurasian teal Anas crecca $(n=46,581)$ were inspected during ringing operations for the presence of the hymenolepidid cloacal cestode Cloacotaenia megalops between 1954 and 1971 while wintering in the Camargue, Southern France. These birds become infected when ingesting seed shrimps (Ostracoda) that act as intermediate hosts, largely while on migration across Western Europe. The prevalence ranged from $4 \%$ to $14 \%$ per year and increased significantly over time. This long-term trend was further supported by studying 366 teal shot in 2006-2008, for which prevalence of C. megalops was $27.6 \%$. We found no evidence to suggest that this increase in prevalence has been caused by an increase in temperature, but eutrophication and an increase in duck densities are potential contributing factors. Adult teal were more likely to be infected than first-year birds and females more so than males, probably due to differences in diet and/or habitat use. Within a given age-sex class, heavier birds were more
\end{abstract}

Communicated by C. Gortázar

A. J. Green $(\bowtie)$

Department of Wetland Ecology,

Estación Biológica de Doñana-CSIC,

Avda. Américo Vespucio s/n,

Sevilla 41092, Spain

e-mail: ajgreen@ebd.csic.es

\section{B. B. Georgiev}

Central Laboratory of General Ecology,

Bulgarian Academy of Sciences,

2 Gagarin Street,

1113 Sofia, Bulgaria

B. B. Georgiev

Department of Zoology, Natural History Museum,

Cromwell Road,

London SW7 5B, UK infected than lighter ones, suggesting low pathogenicity and a causal effect of ingestion rate. Within a year, the highest prevalence was observed in mid-winter.

Keywords Cloacotaenia $\cdot$ Ducks $\cdot$ Helminths . Long-term trends in parasite prevalence - Ostracods . Waterfowl

\section{Introduction}

There has been a growing interest in understanding the dynamics of parasites in ecosystems (Thomas et al. 2005). In the past century, human activities have resulted in substantial large-scale habitat and climate modifications, which influence the ecology and evolution of parasites (Lebarbenchon et al. 2008). Major consequences of anthropogenic global change include widespread increases

A.-L. Brochet $\cdot$ M. Guillemain

Office National de la Chasse et de la Faune Sauvage,

CNERA Avifaune Migratrice,

Le Sambuc,

Arles 13200, France

A.-L. Brochet $\cdot$ M. Gauthier-Clerc

Centre de Recherche de La Tour du Valat,

Le Sambuc,

Arles 13200, France

H. Fritz

CNRS UMR 5558 Biométrie et Biologie Evolutive,

Université Claude Bernard Lyon 1,

Bâtiment 711, 43 bd du 11 novembre 1918,

Villeurbanne cedex 69622, France 
in average temperatures (IPCC 2007) and eutrophication of water bodies (Smith et al. 1999; Savage et al. 2010). Recent studies show sensitivity of parasites and vectors to climate factors (Harvell et al. 2002) and to nutrient loads (Johnson et al. 2007). The effects of parasites on wild host populations may therefore experience similar changes driven by climate or eutrophication (Lebarbenchon et al. 2008). Trophically transmitted parasites may be particularly sensitive to global change, as effects on intermediate hosts may escalate in final hosts, and vice versa.

Parasitic helminths are abundant and diverse in vertebrates, often using invertebrates as intermediate hosts in their life cycles. There are, however, few studies on long-term dynamics of helminth infections in mammals (Théron et al. 1992; Valtonen et al. 2004) or birds (Redpath et al. 2006). Internal parasites are generally invisible without necropsy, and the need to study dead individuals greatly limits sample size. Thus, we currently have limited understanding of the determinants of helminth parasite loads in wild populations of birds or other vertebrates.

Because it occupies the cloaca, the cestode Cloacotaenia megalops (Nitzsch in Creplin 1829) Wolffhügel 1938 (syns. Hymenolepis megalops, Orlovilepis megalops) can be easily observed in live waterfowl (Anseriformes: ducks, geese, and swans) by opening the cloaca and pressing on the surrounding parts of the abdomen with both thumbs (Haukos and Neaville 2003), a technique also used to observe genitalia so as to sex and age waterfowl (e.g., Ogilvie 1978). With a scolex diameter of $1.3 \mathrm{~mm}$ and a body length of 16-30 mm (Spasskaya 1966), C. megalops can be easily detected in situ. It cannot be confused with other parasite species (no staining is needed for identification due to the peculiar external morphology of this species). This facilitates the collection of prevalence data from large numbers of birds during ringing operations. Cloacotaenia megalops has a complex life cycle, with various seed shrimpos (Ostracoda) as intermediate hosts, including the cosmopolitan Heterocypris incongruens, Eucypris inflata, and Cypris pubera (Jarecka 1958; Kotecki 1970; Tolkacheva 1975; Bisset 1976; Gvozdev and Maksimova 1978; Dobrokhotova 1981, 1985) and many waterfowl species as final hosts (Spasskaya 1966; Maksimova 1989). Cloacotaenia megalops is present in Anas dabbling ducks throughout the annual cycle and is infective on both breeding and wintering grounds (Shaw and Kocan 1980; Canaris et al. 1981; Fedynich and Pence 1994).

In this paper, we consider the prevalence of $C$. megalops in Eurasian teal Anas crecca trapped for ringing in the Camargue (Southern France). Using historical data from 17 different wintering seasons from 1954 to 1971 and recent data from 2006 to 2008, we test the following hypotheses: (1) that C. megalops prevalence has changed over time; (2) that prevalence varies with the age, sex, and structural size of teal owing to the influence of these parameters on the ingestion rate of ostracods (e.g., female ducks generally consume more invertebrates than males, Krapu and Reinecke 1992); (3) that prevalence is negatively correlated with body mass, owing to pathogenic effects of C. megalops; and (4) that prevalence changes during the course of a given wintering season, owing to seasonal changes in temperature, duck diet, and ostracod abundance. We discuss the implications of the results for our understanding of the ecology and pathogenicity of C. megalops.

\section{Materials and methods}

Study area and catching methods

Teal were caught in the Camargue, at the Research Centre of Tour du Valat $\left(43^{\circ} 30^{\prime} 28 \mathrm{~N}, 04^{\circ} 40^{\prime} 07 \mathrm{E}\right)$ between $1 \mathrm{st}$ August and 30th April of wintering seasons 1954-1955 to 1970-1971 using standard funnel traps concealed in vegetation (Bub 1991 p. 103). Ducks were sexed and aged (first-year or adult) using plumage criteria and inspection of the cloaca and bursa of Fabricius. The presence or absence of C. megalops was noted upon cloaca examination. Because most infected teal had only one or two cestodes (see results), we analyzed data on the basis of presence or absence of the parasite (i.e., prevalence, see Bush et al. 1997), rather than numbers (i.e., intensity or mean abundance). Only $0.7 \%$ of infected birds carried five or more worms. A total of 46,581 teals were sexed, aged, measured (wing length), weighed, and had their parasite status (number of $C$. megalops) recorded.

Teal have also been ringed in recent years, but plumage variation is now used to age birds without cloacal inspection (Carney 1992). However, we obtained 366 hunter-killed teal shot in seven hunting estates in the Camargue in the winters of 2006-2007 $(n=183)$ and 2007$2008(n=183)$ for a study of gut contents (Brochet et al. 2010). We counted the number of C. megalops present in the cloaca of each bird after dissection. Cloacotaenia megalops is a large, conspicuous species found only in the cloaca, and is readily observed both by visual cloacal inspection in vivo or upon dissection (see "Introduction" section), making these two methods directly comparable. The presence of $C$. megalops is not an indicator of the presence or absence of other internal cestodes.

Temperature data

In order to analyze the relationship between cestode prevalence and temperature variation for the 1954-1971 data set, we first obtained temperature data from the Camargue from the Centre de Recherche de la Tour du 
Valat. Given that we had prevalence data for many months, and taking into account the development time of $C$. megalops (see "Discussion" section), we used mean temperatures (i.e., mean of daily means) for the August to February period inclusive. We then obtained temperature data from two parts of Europe of particular importance for teal on autumn migration towards the Camargue: Denmark and Hungary (Scott and Rose 1996). Data from Copenhagen and Budapest were downloaded from the CISL Research Data Archive (http://dss.ucar.edu/). We calculated mean temperatures from August to December inclusive, to cover the entire autumn migration period.

\section{Statistical analyses}

We used multiple logistic regression (Sokal and Rohlf 1995) to model the probability that a bird had at least one C. megalops as a function of sex, age, Julian date, the winter of examination (from 1954-1955 to 1970-1971) considered as a factor, body mass, and wing length. Day was included as a second-order polynomial so as to allow for potential non-linear patterns across the wintering season. To reduce colinearity between day and day ${ }^{2}$ (Legendre and Legendre 1998), the first of January was considered as day 0, days from August to December being considered as negative values. The interaction body mass * wing length was also included, as well as the interactions between these morphometric variables and age or sex (e.g., wing length * age, body mass * sex, etc.), the interaction sex * age (so as to consider potentially different patterns between the different sex and age classes), and the interaction age * day (because seasonal trends of infection may differ between age classes).

A backwards stepwise model selection procedure was first used: from the most complete model, non-significant terms at $P=0.05$ were gradually removed, starting with interaction terms. Over-dispersion was unlikely given the presence/absence structure of the data and the nature of significant effects was unchanged when we controlled for over-dispersion (results not shown). The extent to which our final model fitted the data was assessed by the ratio of the residual deviance to the number of degrees of freedom (the ideal ratio being one, Crawley 1993). To test the robustness of our results, the same procedure was then repeated using a forward stepwise model selection procedure.

To establish whether there was a change in prevalence over time, we carried out a Pearson correlation between winter (continuous variable in chronological order) and the prevalence of cestodes as indicated by the estimates in our model (i.e., while controlling for sex, age, date, etc.). In order to test the influence of temperature, we calculated correlation coefficients for the relationship between preva- lence in a given year and mean temperatures in the Camargue and at Copenhagen or Budapest, and determined the partial effects of temperature while controlling for winter in a multiple regression. All analyses were carried out with Statistica 6.0 (StatSoft 2001). Confidence intervals $(95 \%)$ for proportions were calculated after the Wilson score method without continuity correction (Newcombe 1998).

\section{Results}

Cestode prevalence from 1954 to 1971

The overall prevalence of $C$. megalops for teal inspected between 1954 and 1971 was $9.2 \%$, ranging from $4 \%$ to $14 \%$ in a given year (Fig. 1). Most infected individuals carried only one $(78 \%)$ or two $(17 \%)$ cestodes. Adults were more likely to be infected than first-year birds and females were more so than males, the difference between sexes being more pronounced in adults (mean prevalence and limits of $95 \%$ confidence intervals: adult females 16.38\% (15.38-17.43); adult males 10.30\% (9.71-10.92); first year females $8.25 \%(7.84-8.67)$; first year males $7.10 \%(6.70-7.52))$.

The final model of the stepwise backwards selection procedure for prevalence retained sex, age, sex * age, year, body mass, and day and day squared, which all had significant contributions in predicting the probability that a teal was infected by $C$. megalops (Table 1). The complete model including all explanatory variables above provided a good fit to the data, since deviance was equal to 27,653.6, while the number of degrees of freedom was 46,558 (a ratio of 0.59 ). The final model after forward stepwise selection contained exactly the same list of variables.

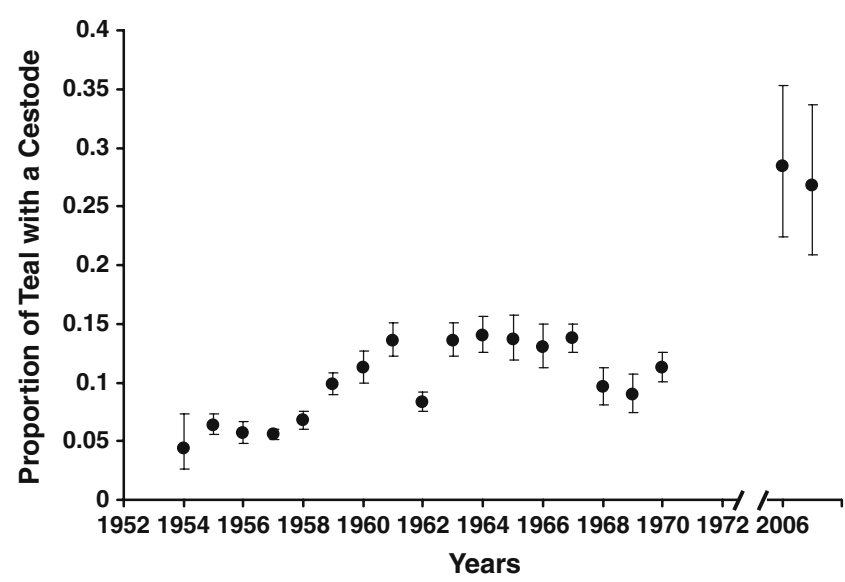

Fig. 1 Average C. megalops prevalence per winter for teal inspected visually from 1954 to 1971 , and teal dissected from 2006 to 2008 . Vertical bars show the lower and upper limits of $95 \%$ confidence intervals 
Table 1 Results of the stepwise backwards logistic regression to predict the probability that a teal carried a cestode between 1954 and 1971

\begin{tabular}{lcccc}
\hline & Estimate & SE (estimate) & Wald statistic & $P$ value \\
\hline Sex (female) & 0.212 & 0.018 & 130.86 & 165.62 \\
Age (adult) & 0.231 & 0.018 & 13.66 & $<0.0001$ \\
Sex * age & 0.063 & 0.017 & 445.90 & 0.0002 \\
Year & $-^{\mathrm{a}}$ & $-^{\mathrm{a}}$ & 44.17 & $<.16$ \\
Body mass & $3.1 \times 10^{-3}$ & $4.6 \times 10^{-4}$ & $0.0001^{\mathrm{a}}$ \\
Day & $1.6 \times 10^{-3}$ & $5.3 \times 10^{-4}$ & 19.86 & 0.0001 \\
Day $^{2}$ & $-4.1 \times 10^{-5}$ & $9 \times 10^{-6}$ & $<0.0001$ \\
\hline
\end{tabular}

The complete model included sex, age, sex * age, year, body mass, wing length, sex * body mass, sex * wing length, age * body mass, age * wing length, body mass $*$ wing length, day, and day ${ }^{2}$. Only the final model is presented. Estimates are not given here for all 17 levels of the discontinuous year factor. The final model provided a good fit to the data (see text)

${ }^{\text {a }}$ No single estimate was available for this factor, which has 17 modalities

Heavier birds were more likely to carry cestodes than lighter ones (Table 1). The prevalence of cestodes differed between years, increasing as the years progressed (Fig. 1), with a significant positive correlation between winter in chronological order and the estimate for prevalence in our model $(r=0.62, P=0.008, n=17)$. There was positive serial correlation of residuals $(r=0.50, P=0.04$, Durbin-Watson $d=0.83$ ); hence, the analysis was repeated using only every second year. There remained a relationship between winter and estimated prevalence $(r=0.72, P=0.028, n=9)$, without evidence of serial correlation of residuals $(r=0.22, P>0.7$, $d=1.79)$. Within a year, the model estimates for day and day $^{2}$ indicated that the highest prevalence was in midwinter in December and early January (see also Fig. 2).

We found no evidence to suggest that temperature change was related to this increase in prevalence, with no evidence of a temperature increase in the Camargue, Copenhagen, or Budapest over this period $(r<0.02, P>0.9)$. Pearson correlation coefficients between prevalence and temperature were

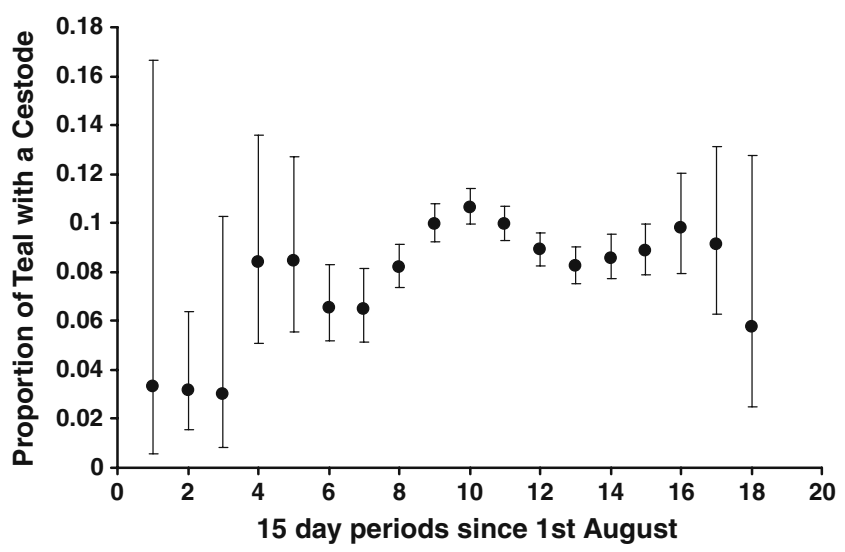

Fig. 2 Average C. megalops prevalence for teal inspected visually from 1954 to 1971, grouped together by 15-day periods since 1st August (i.e., period ten is the second half of December). Vertical bars show the lower and upper limits of $95 \%$ confidence intervals very low (range $-0.052-0.114, P>0.6$ ). Partial effects of temperature in a multiple regression controlling for winter were very weak $(P>0.5)$.

\section{Recent data from hunter-killed birds}

The overall prevalence of $C$. megalops for teal shot in the winters of 2006-2007 or 2007-2008 was $28.4 \%$ and $26.8 \%$, respectively. This was much higher than the prevalence recorded in any winter between 1954 and 1971 (Fig. 1, twotailed two-sample $t$ test, $t=7.23, \mathrm{df}=17, P<0.0001$ ).

\section{Discussion}

Owing to the large size of our dataset, our study provides a detailed understanding of the factors determining the prevalence of a trophically transmitted cestode parasite. Teal are long-distance migrants with a broad wintering range including the Camargue and other parts of the Mediterranean region, and a broad breeding range in northern Eurasia (Kear 2005). They are omnivorous and consume ostracods throughout the year (Olney 1963; Danell and Sjöberg 1980; Gaston 1992). Cloacotaenia megalops can therefore infest teal at any stage of the annual cycle (see also Shaw and Kocan 1980; Canaris et al. 1981; Fedynich and Pence 1994). Although the lifespan of C. megalops is unknown, its development (from infestation to the beginning of oviproduction) in mallards Anas platyrhynchos takes 6 weeks (Kotecki 1970). Given their rapid migrations (Lebarbenchon et al. 2009), the prevalence for teals wintering in the Camargue is a result of infestation events that may have occurred across Western Europe. Thus, the long-term trend probably reflects changes in host-parasite dynamics averaged out over a huge area. At a local scale, such dynamics may be much more variable, with a less discernable trend between years. 
Given its low pathogenicity and considerable development time, teal must often excrete $C$. megalops eggs a long distance from the point of infection, making them excellent vectors for parasite dispersal (Lebarbenchon et al. 2009).

We found a long-term increase in the prevalence of C. megalops in Camargue teal before the 1970s, which was supported by the even higher values recorded 35 years later. Although the methods used in the two time periods (cloacal inspection of live birds before the 1970s, dissection in the 2000s) should ideally be compared in the same birds, the results are consistent for the two periods. Furthermore, Haukos and Neaville (2003) noted a steady increase in the prevalence of C. megalops in Anas dabbling ducks wintering in Texas between 1986 and 2000, suggesting widespread increases in C. megalops infections in migratory waterfowl. As the area of habitat available for wintering ducks has decreased due to wetland loss, waterfowl have often become more concentrated in limited areas, promoting transmission of cestodes and other diseases (Shaw and Kocan 1980; Lebarbenchon et al. 2007). A generalized increase since the 1950s in the density of teal during migration and winter in Western Europe is a possibility, given that wetland loss has been widespread, whereas teal numbers appear to have been roughly stable in the Mediterranean flyway, and have been increasing in North-Western Europe (Delany and Scott 2006). Furthermore, C. megalops infects other duck species, so the dynamics of infections in teal are also likely to be affected by changes in densities of other ducks. Long-term trends in the Camargue and across Europe vary between duck species (Delany and Scott 2006; Isenmann 2004).

During experiments, the time lag between infection of ostracods by $C$. megalops and the development of cysticercoids (larval stage able to infest ducks) in them was 12-18 days (Jarecka 1958; Kotecki 1970). However, studies of other hymenolepidid cestodes show that development time is temperature-dependent (Bondarenko and Kontrimavichus 2006). Ambient temperatures have increased across the range of the teal since 1970 owing to climate change (IPCC 2007). However, we found no evidence that the increased prevalence of $C$. megalops in ducks over time reflects an accelerated rate of parasite circulation due to increased temperature, and temperatures did not increase between 1954 and 1971 (see also Devictor et al. 2008).

Ostracods themselves are sensitive to environmental change (Ruiz et al. 2005). Eutrophication is another potential cause of the long-term increase in C. megalops prevalence, has led to a gradual decrease in water quality across Europe since 1950 (Smith et al. 1999; Savage et al. 2010), and has caused an increase in prevalence of trematodes that cause malformations in amphibians (Johnson et al. 2007). Heterocypris incongruens appears to be the most important intermediate host for the circulation of C. megalops (Kotecki 1970; Tolkacheva 1975; Bisset 1976; Dobrokhotova 1981, 1985) and is a good indicator for eutrophication (Külköylüoğlu 2004). Other major changes in the Camargue include an increasingly artificial management of hunting estates, leading to drastic changes in hydrology and decreased overall salinity of wetlands (Tamisier and Grillas 1994) that may somehow have increased circulation of C. megalops, e.g., by benefiting ostracods.

Cestode fauna in avian hosts is directly related to the type of food ingested (Drobney et al. 1983). The prevalence of helminths is often greater in adult female waterfowl and in first-year birds because of a greater amount of invertebrates in their diet (Drobney et al. 1983; Krapu and Reinecke 1992; Haukos and Neaville 2003). We also found adult female teal to have the highest prevalence and first-year males to have the lowest. In teal wintering in Texas, Haukos and Neaville (2003) found different results from ours, with adult males having significantly lower $C$. megalops prevalence than adult females (as in our study), but also than first-year birds of either sex, with no significant differences between the other three age-sex classes. Although differences in diet between study areas may explain such inconsistencies, differences in prevalence with age or sex may also be related to differences in habitat use at a local or flyway scale, and an increase in explorative movements and diversity of habitats used will tend to increase exposure to parasites (Gray et al. 1989; Figuerola and Green 2000).

Although C. megalops may occasionally be the cause of death in waterfowl (Price 1985), we recorded a positive correlation between teal body mass and prevalence. This is contrary to what would be expected if C. megalops had a marked pathogenic effect on teal, and suggests that this parasite generally has no detectable effect on host physical condition. Indeed, trophically transmitted parasites have evolved to decrease their pathology for the final host (Geraci and St. Aubin 1987). Teal with a greater mass tend to be structurally larger and/or have greater fat reserves and so are likely to have consumed more food, including infected ostracods. Similarly, Gray et al. (1989) found the abundance of three helminth parasites to increase in mallards with a larger body size or with larger fat stores. On the other hand, body mass may potentially be confounded with individual differences in local dispersion distances at night (Guillemain et al. 2007), which may in turn influence infection rates through the use of different habitat types.

Helminth infections are generally short-lived, such that decreased availability in winter of invertebrates acting as intermediate hosts leads to declines in helminth prevalence during the winter (Buscher 1965; Shaw and Kocan 1980; Dronen et al. 1994). Haukos and Neaville (2003) found the 
prevalence of C. megalops in teal to decrease from $33 \%$ in October to $25 \%$ in January, although this trend was not statistically significant. In other Anas species in North America, infections of $C$. megalops peaked in August (Buscher 1965). We found the proportion of teal infected with $C$. megalops to peak around midwinter. There are two possible explanations for this. Firstly, teal may be most readily infected in early winter when ostracods remain abundant and active, but as temperatures drop in midwinter, the availability of ostracods decreases. The time lag required for the development of adult cestodes explains why the peak prevalence is in midwinter. Secondly, the phenology of $C$. megalops infection may be the product of differences in cestode prevalence between teal with different migration patterns. Teal ringed in midwinter tend to spend a longer time wintering in the Camargue, while those ringed in early and late winter are more likely to be migrating to and from sites further south (Caizergues et al., in preparation). Thus, our results might reflect a higher prevalence of cestodes in teal wintering in the Camargue than in those wintering further south (e.g., if teal are more likely to feed on infected ostracods in the Camargue).

Clearly, detailed research on the dynamics of C. megalops in intermediate ostracod hosts is required before the dynamics of this cestode in teal can be fully understood. The dynamics of $C$. megalops in other European duck populations should also be studied to establish whether longterm increases in prevalence are widespread.

Acknowledgments We are grateful to Luc Hoffmann, Hubert Kowalski, Heinz Hafner, Alan Johnson, and others who ringed teal at the Tour du Valat over 25 years. Marc Lutz, Paul Isenmann, and the Centre de Recherche sur la Biologie des Populations d'Oiseaux (Muséum National d'Histoire Naturelle, Paris) helped to computerize the ringing database. Mr Cordesse, Herbinger, Rayssac, Grossi, Lecat, and Arnihac and members of the Tour du Valat hunting group allowed us to sample freshly shot birds. We also thank J.-B. Mouronval and J. Fuster for help sampling digestive tracts, P. Almaraz for help locating temperature data, and anonymous referees for improving the manuscript. A.-L. Brochet was funded by a Doctoral grant from Office National de la Chasse et de la Faune Sauvage, with additional funding from a research agreement between ONCFS, the Tour du Valat, Laboratoire de Biométrie et de Biologie Evolutive (UMR 5558 CNRS Université Lyon 1), and the Doñana Biological Station (CSIC). This work also received funding from the Agence Nationale de la Recherche through the Santé Environnement Santé Travail scheme (contract number 2006-SEST-22).

\section{References}

Bisset SA (1976) A possible intermediate host for Cloacotaenia megalops (Cestoda: Hymenolepididae), a common parasite of waterfowl in New Zealand. Mauri Ora 4:75-77

Bondarenko SK, Kontrimavichus VL (2006) Fundamentals of Cestodology, vol. 14. In: Movsesyan SO (ed) Aploparaksidae of wild and domesticated birds. Nauka, Moscow, p 433, In Russian
Brochet AL, Guillemain M, Fritz H, Gauthier-Clerc M, Green AJ (2010) Plant dispersal by teal (Anas crecca) in the Camargue: duck guts are more important than their feet. Freshw Biol 55:1262-1273

Bub H (1991) Bird trapping and bird banding. A handbook for trapping methods all over the world. Cornell University Press, New York

Buscher HN (1965) Dynamics of the intestinal helminth fauna in three species of ducks. J Wildl Manage 29:772-781

Bush AO, Lafferty KD, Lotz JM, Shostak AW (1997) Parasitology meets ecology on its own terms: Margolis et al. revisited. J Parasitol 83:575-583

Canaris AG, Mena AC, Bristol JR (1981) Parasites of waterfowl from Southwest Texas. 3. The Green-Winged Teal, Anas crecca. J Wildl Dis 17:57-64

Carney SM (1992) Species, age and sex identification of ducks using wing plumage. U.S. Department of the interior, U.S. Fish and Wildlife Service, Washington, p 144

Crawley MJ (1993) Glim for ecologists. Blackwell Scientific, Oxford

Danell K, Sjöberg K (1980) Foods of wigeon, teal, mallard and pintail during the summer in a northern Swedish lake. Viltrevy 11:141167

Delany S, Scott D (2006) Waterbird population estimates, 4th edn. Wetlands International, Wageningen

Devictor V, Julliard R, Couvet D, Jiguet F (2008) Birds are tracking climate warming, but not fast enough. Proc R Soc B Biol Sci 275:2743-2748

Dobrokhotova OV (1981) Host-parasitic system "larvae of cestodes crustaceans" in biocenosis of Kurgaldzhin lakes. In: Gvozdev EV, Panin V, Sidorov EG (eds) Parasites as components of water and ground biocenoses of Kazakhstan. Nauka, Alma-Ata, pp 1827 (In Russian)

Dobrokhotova OV (1985) Biocoenotic relationship between ostracods and hymenolepidids of marsh birds in water bodies of Kazakhstan. In: Gvozdev EV (ed) Helminths of animals in the ecosystems of Kazakhstan. Nauka, Alma-Ata, pp 22-44, In Russian

Drobney RD, Train CT, Fredrickson LH (1983) Dynamics of the platyhelminth fauna of wood ducks in relation to food-habits and reproductive state. J Parasitol 69:375-380

Dronen NO, Lindsey JR, Ross LM, Krise GM (1994) Helminths from mallard ducks, Anas platyrhynchos, wintering in the Post-Oak Savanna of South-Central Texas. Southwest Nat 39:203-205

Fedynich AM, Pence DB (1994) Helminth community structure and pattern in a migratory host (Anas platyrhynchos). Can J Zool 72:496-505

Figuerola J, Green AJ (2000) Haematozoan parasites and migratory behaviour in waterfowl. Evol Ecol 14:143-153

Gaston GR (1992) Green-winged Teal ingest epibenthic meiofauna. Estuaries 15:227-229

Geraci JR, St. Aubin DJ (1987) Effects of parasites on marine mammals. Int J Parasitol 17:407-414

Gray CA, Gray PN, Pence DB (1989) Influence of social-status on the helminth community of late-winter mallards. Can J Zool 67:1937-1944

Guillemain M, Fritz H, Johnson AR, Simon G (2007) What type of lean ducks do hunters kill? Weakest local ones rather than migrants. Wildlife Biol 13:102-107

Gvozdev EV, Maksimova AP (1978) Eucypris inflata, an intermediate host of avian cestodes in the biocoenosis of Lake Tengiz. Parazitologiya 12:339-344 (In Russian)

Harvell CD, Mitchell CE, Ward JR, Altizer S, Dobson AP, Ostfeld RS, Samuel MD (2002) Climate warming and disease risks for terrestrial and marine biota. Science 296:2158-2162

Haukos DA, Neaville J (2003) Spatial and temporal changes in prevalence of a cloacal cestode in wintering waterfowl along the Gulf Coast of Texas. J Wildl Dis 39:152-160 
IPCC 2007: Climate Change 2007: Synthesis Report. Contribution of Working Groups I, II and III to the Fourth Assessment Report of the Intergovernmental Panel on Climate Change [Core Writing Team, Pachauri, R.K and Reisinger, A. (eds.)]. IPCC, Geneva, Switzerland, $104 \mathrm{pp}$

Isenmann P (2004) Les oiseaux de Camargue et leurs habitats: Une histoire de cinquante ans 1954-2004. Ecologie. Buchet-Chastel, Paris

Jarecka L (1958) Life cycle of Orlovilepis megalops (Nitzsch in Creplin) Spassky et Spasskaja, 1954. Bull 'Académie Pol Sciences Cl II Sér Sci Biol 6:335-338

Johnson PTJ, Chase JM, Dosch KL, Hartson RB, Gross JA, Larson DJ, Sutherland DR, Carpenter SR (2007) Aquatic eutrophication promotes pathogenic infection in amphibians. Proc Natl Acad Sci USA 104:15781-15786

Kear J (2005) Bird families of the world: ducks, geese and swans. Oxford University Press, Oxford

Kotecki N (1970) Circulation of the cestode fauna Anseriformes in the municipal zoological garden in Warszawa. Acta Parasitol Pol 17:329-355

Krapu GL, Reinecke KJ (1992) Foraging ecology and nutrition. In: Batt BDJ, Afton AD, Anderson MG, Ankney CD, Johnson DH, Kadlec JA, Krapu GL (eds) Ecology and management of breeding waterfowl. University of Minnesota Press, Minneapolis and London, pp 1-29

Külköylüoğlu O (2004) On the usage of ostracods (Crustacea) as bioindicator species in different aquatic habitats in the Bolu region, Turkey. Ecol Indic 4:139-147

Lebarbenchon C, Poulin R, Gauthier-Clerc M, Thomas F (2007) Parasitological consequences of overcrowding in protected areas. EcoHealth 3:303-307

Lebarbenchon C, Brown SP, Poulin R, Gauthier-Clerc M, Thomas F (2008) Evolution of pathogens in a man-made world. Mol Ecol $17: 475-484$

Lebarbenchon C, Albespy F, Brochet AL, Grandhomme V, Renaud F, Fritz H, Green AJ, Thomas F, van der Werf S, Aubry P, Guillemain M, Gauthier-Clerc M (2009) Spread of avian influenza viruses by common teal (Anas crecca) in Europe. PLoS ONE 4(10): 7289

Legendre P, Legendre L (1998) Numerical ecology. Elsevier, Amsterdam

Maksimova AP (1989) Hymenolepidid cestodes of aquatic birds in Kazakhstan. Alma-Ata, Nauka, p 224, In Russian

Newcombe RG (1998) Two-sided confidence intervals for the single proportion: comparison of seven methods. Stat Med 17:857-872
Ogilvie MA (1978) Wild Geese. T. \& A.D. Poyser, Berkhamsted, p 350

Olney PJS (1963) The food and feeding habits of teal Anas crecca L. Proc Zool Soc (London) 140:169-210

Price JI (1985) Immunizing Canada Geese against Avian Cholera. Wildl Soc Bull 13:508-515

Redpath SM, Mougeot F, Leckie FM, Elston DA, Hudson PJ (2006) Testing the role of parasites in driving the cyclic population dynamics of a gamebird. Ecol Lett 9:410-418

Ruiz F, Abad M, Bodergat AM, Carbonel P, Rodriguez-Lazaro J, Yasuhara M (2005) Marine and brackish-water ostracods as sentinels of anthropogenic impacts. Earth Sci Rev 72:89-111

Savage C, Leavitt PR, Elmgren R (2010) Effects of land use, urbanization, and climate variability on coastal eutrophication in the Baltic Sea. Limnol Oceanogr 55:1033-1046

Scott DA, Rose PM (1996) Atlas of Anatidae populations in Africa and Western Eurasia. Wetlands International, Wageningen

Shaw MG, Kocan AA (1980) Helminth fauna of waterfowl in Central Oklahoma. J Wildl Dis 16:59-64

Smith VH, Tilman GD, Nekola JC (1999) Eutrophication: impacts of excess nutrient inputs on freshwater, marine, and terrestrial ecosystems. Environ Pollut 100:179-196

Sokal RR, Rohlf FJ (1995) Biometry: the principles and practice of statistics in biological research, 3rd edn. W. H. Freeman and Co., New York

Spasskaya LP (1966) Cestodes of birds in the USSR. Hymenolepididae. Moscow, Nauka, 698pp. (In Russian)

StatSoft (2001) Statistica 6.0. Tulsa, USA

Tamisier A, Grillas P (1994) A review of habitat changes in the Camargue: an assessment of the effects of the loss of biological diversity on the wintering waterfowl community. Biol Conserv 70:39-47

Théron A, Pointier JP, Morand S, Imbert-Establet D, Borel G (1992) Longterm dynamics of natural populations of Schistosoma mansoni among Rattus rattus in patchy environment. Parasitology 104:291-298

Thomas F, Renaud F, Guégan JF (eds) (2005) Parasitism and ecosystems. Oxford University Press, Oxford

Tolkacheva LM (1975) Crustaceans - intermediate hosts of cestodes of aquatic and marsh birds in the Karasuk lakes (USSR). Tr Biologicheskogo Inst Sibirskoe Otdelenie Akad Nauk SSSR 17:114-143 (In Russian)

Valtonen ET, Helle E, Poulin R (2004) Stability of Corynosoma populations with fluctuating population densities of the seal definitive host. Parasitology 129:635-642 